\title{
The maternal prepregnancy body mass index and the risk of attention deficit hyperactivity disorder among children and adolescents: a systematic review and meta-analysis
}

\author{
Ensiyeh Jenabi, $\mathrm{PhD}^{1}$, Saied Bashirian, $\mathrm{PhD}^{2}$, Salman Khazaei, $\mathrm{PhD}^{3}$, Zohreh Basiri MSc ${ }^{4}$ \\ ${ }^{7}$ Autism Spectrum Disorders Research Center, Hamadan University of Medical Sciences, Hamadan, ${ }^{2}$ Social Determinants of Health Research Center, Hamadan \\ University of Medical Sciences, Hamadan, ${ }^{3}$ Research Center for Health Sciences, Hamadan University of Medical Sciences, Hamadan, Iran, ${ }^{4}$ Master of Science \\ Epidemiology, Faculty of Science, University of Melbourne, Melbourne, Australia
}

Background: Attention deficit hyperactivity disorder (ADHD) symptoms have a major impact on individuals, families, and society. Therefore identification risk factors of ADHD are a public health priority.

Purpose: This is meta-analysis evaluated the association between maternal prepregnancy body mass index and the risk of $\mathrm{ADHD}$ among the resulting offspring.

Methods: The search identified studies published through December 2018 in the PubMed, Web of Science, and Scopus databases. The odds ratios (ORs) or hazard ratios (HRs) with $95 \%$ confidence intervals (Cl) extracted from eligible studies were used as the common measure of association among studies.

Results: A significant association was found between overweight women and the risk of ADHD among children with the pooled $\mathrm{HR}$ and $\mathrm{OR}$ estimates (HR, 1.27 and $95 \% \mathrm{Cl}, 1.17-1.37$; OR, 1.28 and $95 \%$ $\mathrm{Cl}, 1.15-1.40$, respectively). This association was significant between obese women and the risk of ADHD among children and adolescents with the pooled estimates of $\mathrm{HR}$ and $\mathrm{OR}(\mathrm{HR}, 1.65$ and $95 \% \mathrm{Cl}$, $1.55-1.76$; OR, 1.42 and $95 \% \mathrm{Cl}, 1.23-1.61)$.

Conclusion: The current epidemiological studies present sufficient evidence that prepregnancy overweight and obesity are significantly associated with an increased risk of ADHD among children and adolescents. These findings provide a new approach to preventing ADHD by controlling weight gain in the prenatal period, which should be considered by policymakers.

Key words: Attention deficit disorder with hyperactivity, Body mass index, Pregnancy

\section{Key message}

Question: Is there an association between maternal prepregnancy BMI and offspring ADHD?

Finding: The findings of this study showed a significant association between prepregnancy overweight and obesity and the risk of ADHD among children according to pooled estimates of HR and OR.

Meanings: These findings provide a new approach to preventing ADHD by controlling prenatal weight gain that should be considered by policymakers.

\section{Introduction}

The Diagnostic and Statistical Manual of Mental Disorders 4th edition defines attention deficit hyperactivity disorder (ADHD) as a neurobehavioral disorder characterized by pervasive
Corresponding author: Salman Khazaei, PhD Research Center for Health Sciences, Hamadan University of Medical Sciences, Hamadan, Iran Tel \& Fax: +98-81-38380717

E-mail: salmankhazaei61@gmail.com

https://orcid.org/0000-0001-5918-2310

Received: 20 Fabruary, 2019

Revised: 27 April, 2019

Accepted: 17 May, 2019
Copyright (C) 2019 by The Korean Pediatric Society

This is an open-access article distributed under the terms of the Creative Commons Attribution NonCommercial License (http://creativecommons.org/ licenses/by-nc/4.0/) which permits unrestricted noncommercial use, distribution, and reproduction in any medium, provided the original work is properly cited. 
and impairing symptoms of inattention, hyperactivity, and impulsivity. ${ }^{1)} \mathrm{ADHD}$ is one of the most common mental health disorders in childhood, with an estimated global prevalence of 5.2\%."

Although genetics plays a significant role in the development of ADHD, 10\%-40\% of the variance associated with ADHD is related to environmental factors. ${ }^{3)}$ Environmental factors may interact with genetic influences or participate in the casual pathway of ADHD and its symptoms. ${ }^{4,5}$ Given that the symptoms of ADHD appear early in life, the prenatal environment might play an important role in its development. Previous studies identified numerous prenatal risk factors of ADHD, such as premature birth, low birth weight, number of pregnancies and deliveries, infancy complications, maternal substance use, and stress during pregnancy. ${ }^{6,7)}$

Studies have shown that prepregnancy maternal overweight or obese status may be associated with central nervous system problems in the fetus and newborn, including ADHD. ${ }^{8-10)}$

Maternal conditions and care in the prepregnancy period play an important role in preventing adverse pregnancy outcomes. ${ }^{11}$ Given that ADHD symptoms have a major impact on individuals, families, and society and feature continuous complications through adulthood, the identification of its risk factors is a public health priority for health policymakers.

Although several studies have shown a significant association between maternal prepregnancy body mass index (BMI) and offspring ADHD, several other studies have not. Thus, the status of this association is uncertain. Accordingly, the current meta-analysis aimed to investigate the association between maternal prepregnancy $\mathrm{BMI}$ and offspring $\mathrm{ADHD}$.

\section{Methods}

\section{Data sources}

To evaluate the association between maternal prepregnancy BMI and the risk of ADHD among children and adolescents, the PRISMA (Preferred Reporting Items for Systematic Reviews and MetaAnalyses) statement checklist was used to assess the retrieved studies and raise the study quality herein. ${ }^{12)}$

\section{Search strategy}

The search identified studies published until December 2018 in the PubMed, Web of Science, and Scopus databases. The search was performed using the following principal terms categorized in 2 groups: (1) ADHD, attention deficit disorder with hyperactivity, attention deficit disorder hyperactivity, attention deficit disorder hyperactivity, child attention deficit disorder; and (2) body size, obese, obesity, overweight, BMI, and prepregnancy (or prepregnancy).

\section{Inclusion and exclusion criteria}

Studies that systematically assessed the association between maternal prepregnancy BMI and the risk of $\mathrm{ADHD}$ among children and adolescents were included. Inclusion criteria were BMI divided according to World Health Organization category: underweight $\left(<18.5 \mathrm{~kg} / \mathrm{m}^{2}\right)$, normal weight $\left(18.5-24.9 \mathrm{~kg} / \mathrm{m}^{2}\right)$, overweight (25$\left.29.9 \mathrm{~kg} / \mathrm{m}^{2}\right)$, and obese $\left(\geq 30 \mathrm{~kg} / \mathrm{m}^{2}\right)$. Reviews, letters to the editor, and case reports were excluded. ${ }^{13)}$

\section{Data extraction}

The study selection process was conducted by 2 investigators (EJ and SK). Any disagreements were decided by a third author. The datasheet used for the extraction included publication year, first author, country, study design, maternal prepregnancy BMI and ADHD, diagnostic criteria of ADHD, sample size, hazard ratio (HR) and rate ratio (RR) and their associated 95\% confidence intervals (CI), adjustment, child's age, and study quality.

\section{Quality assessment}

The methodology quality assessment of the studies included in the present meta-analysis was performed using the NewcastleOttawa Scale. ${ }^{14)}$ Two investigators conducted the quality assessment independently and divided the studies into low quality $(<7$ points $)$ and high quality ( $\geq 7$ points).

\section{Statistical analysis}

The HRs or RRs with 95\% CI from eligible studies were used as the common measure of the association among studies. Heterogeneity across studies was addressed using the $I^{2}$ statistic. Low, medium, and high heterogeneity were defined by $I^{2}$ statistic values of 25\%, 50\%, and 75\%, respectively.

Publication bias was assessed using the Begg and Egger's regression model. ${ }^{15)}$ The statistical meta-analysis was performed using Stata ver. 13 (Stata Corp., College Station, TX, USA).

\section{Results}

\section{Description of studies}

In the primary search, 505 studies were identified. Of them, we excluded 166 duplicate papers. In the next stage, 322 papers were excluded after the title and abstract screening and 9 papers were excluded after the full-text screening. Finally, 10 papers ${ }^{9,10,16-23)}$ with a total of 1,464,097 participants were included in the analysis. All studies were of cohort design. A flowchart of the selection process is shown in Fig. 1.

In the present meta-analysis, the confounding variables of the association between maternal prepregnancy BMI and the risk of ADHD among children and adolescents included socioeconomic status, smoking during pregnancy, maternal psychiatric diagnoses, 
year of birth, mother's country of birth, parental age, gestational age, birth weight, child sex, maternal education, and maternal age at delivery (Table 1). All studies in this meta-analysis were adjusted for these confounding variables.

\section{Main analysis}

A forest plot of the association between maternal prepregnancy BMI and risk of ADHD among children and adolescents is shown in Figs. 2 and 3. Van der Burg et al. ${ }^{19)}$ reported the association between maternal prepregnancy BMI and risk of ADHD based on separate teacher/parent ratings of ADHD symptoms.

A significant association was found between overweight women and risk of ADHD among children based on the pooled estimates of $\mathrm{HR}$ and OR, respectively (HR, 1.27 and 95\% CI, 1.17-1.37; OR, 1.28 and 95\% CI, 1.15-1.76) (Fig. 2). This association was significant

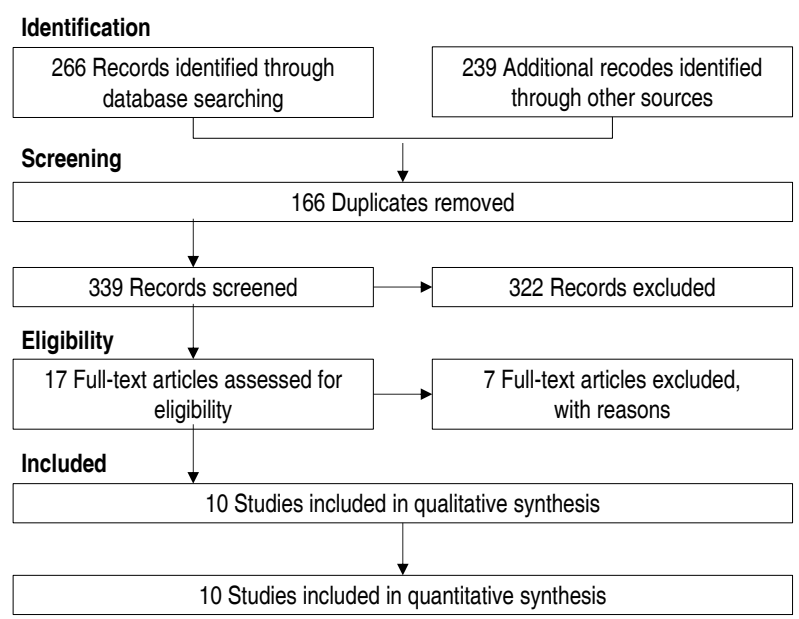

Fig. 1. Diagram of studies through the different phases of the metaanalysis. between obese women and risk of ADHD among children and adolescents based on the pooled estimates of HR and OR, respectively (HR, 1.65 and 95\% CI, 1.55-1.76; OR, 1.42 and 95\% CI, 1.231.61) (Fig. 3). There was medium and low heterogeneity among the studies reporting on the risk $\mathrm{ADHD}$ in children based on $\mathrm{HR}$ in overweight and obese women, respectively $\left(I^{2}=59.3 \%, P=0.117\right)$ $\left(I^{2}=17.2 \%, P=0.299\right)$. There was no heterogeneity in the studies reporting the risk of $\mathrm{ADHD}$ among children and adolescents based on OR in overweight women $\left(I^{2}=0.0 \%, P=0.608\right)$. The heterogeneity based on OR in obese women was low $\left(I^{2}=0.02 \%, P=0.427\right)$.

The $P$ values for Begg and Egger's regression were 0.600 and 0.068 in overweight and obese women were 0.697 and 0.954 , respectively. Therefore, we did not observe publication bias among studies.

\section{Study quality}

All studies in this meta-analysis had high methodology quality according to the Newcastle-Ottawa Scale (Table 1).

\section{Subgroup analysis}

The subgroup analysis was conducted based on teacher/parentidentified ADHD symptoms among children and adolescents in European countries and the USA. The pooled results based on ORs of the teacher/parent-identified ADHD symptoms and overweight women studies were 1.33 (95\% CI, 0.95-1.70) and 1.26 (95\% CI, 1.12-1.41), while those in obese women were 1.42 (95\% CI, 0.702.13) and 1.47 (95\% CI, 1.25-1.68), respectively. There was no significant association in teacher-identified ADHD symptoms among children and adolescents and overweight and obese women (Table 2). There was no significant association in ADHD symptoms among children and adolescents and overweight women in European countries and the USA, but this association was significant in obese women in the USA (OR, 1.44; 95\% CI, 1.23-1.66) (Table 2).

Table 1. Results of the studies included in the present meta-analysis

\begin{tabular}{|c|c|c|c|c|c|c|c|c|c|c|}
\hline Study & Country & Design & $\begin{array}{l}\text { Sample } \\
\text { size }\end{array}$ & $\begin{array}{l}\text { Rated ADHD } \\
\text { symptoms }\end{array}$ & $\begin{array}{l}\text { Body mass } \\
\text { index }\end{array}$ & Estimate & Adjustment & $\begin{array}{l}\text { Child age in } \\
\text { diagnose (yr) }\end{array}$ & Autism criteria & Quality \\
\hline Chen et al. $(2014)^{16)}$ & Sweden & Cohort & 673,632 & Parents & Measured & Hazard ratio & Adjusted & $9-17$ & DSM-V, ICD-10 & High \\
\hline van der Burg et al. $(2007)^{19)}$ & Netherland & Cohort & 764 & Parents/teacher & Self-reported & Odds ratio & Adjusted & 10 & DSM-V & High \\
\hline Rodriguez et al. $(2008)^{9)}$ & $\begin{array}{l}\text { Denmark, } \\
\text { Finland, } \\
\text { Sweden }\end{array}$ & Cohort & 14,519 & Teacher & Measured & Odds ratio & Adjusted & $7-8$ & $\mathrm{SDQ}, \mathrm{RB} 2$ & High \\
\hline Jo et al. $(2015)^{21)}$ & USA & Cohort & 1,311 & Parents & Self-reported & Odds ratio & Adjusted & 6 & $\begin{array}{l}\text { By doctor or other } \\
\text { health professional }\end{array}$ & High \\
\hline Mikkelsen et al. (2017) & Denmark & Cohort & 38,314 & Parents & Self-reported & Odds ratio & Adjusted & 7 & $\operatorname{SDQ}$ & High \\
\hline Kong et al. $(2018)^{17)}$ & Finland & Cohort & 649,043 & Parents & Measured & Hazard ratio & Adjusted & 11 & ICD-10 & High \\
\hline Rodriguez (2010) ${ }^{10)}$ & Sweden & Cohort & 1,714 & Teacher & Measured & Odds ratio & Adjusted & 5 & DSM-V & High \\
\hline Buss et al. (2012) & USA & Cohort & 174 & Parents & Measured & Odds ratio & Crude & 7.30 & ICD-9 & High \\
\hline Li et al. (2016) & USA & Cohort & 2,734 & Parents & Self-reported & Odds ratio & Crude & $3.6-9$ & DSM-V & High \\
\hline
\end{tabular}

ADHD, attention deficit hyperactivity disorder; DSM-V, Diagnostic and Statistical Manual of Mental Disorders, fifth edition; ICD-10, International Statistical Classification of Diseases, 10th revision; ICD-9, International Statistical Classification of Diseases, ninth revision; SDQ, Strengths and Difficulties Questionnaire. 


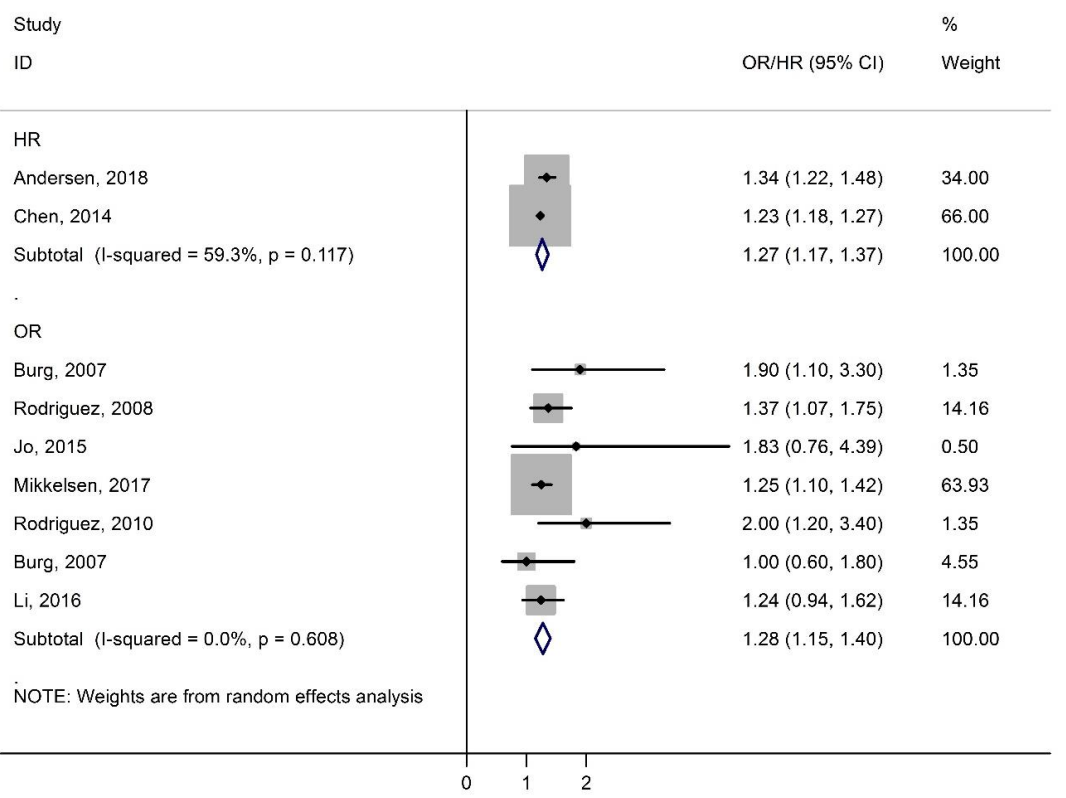

Fig. 2. Association between maternal prepregnancy overweight and risk of attention deficit disorder with hyperactivity among children. $\mathrm{OR}$, odds ratio; $\mathrm{HR}$, hazard ratio; $\mathrm{Cl}$, confidence interval.

\begin{tabular}{|c|c|c|c|}
\hline \multicolumn{3}{|l|}{ Study } & $\%$ \\
\hline ID & & $\mathrm{OR} / \mathrm{HR}(95 \% \mathrm{Cl})$ & Weight \\
\hline \multicolumn{4}{|l|}{$\mathrm{HR}$} \\
\hline Andersen, 2018 & $\leftarrow$ & $1.57(1.35,1.82)$ & 17.14 \\
\hline Chen, 2014 & - & $1.64(1.57,1.73)$ & 73.29 \\
\hline Kong, 2018 & $\leftarrow$ & $1.88(1.58,2.23)$ & 9.57 \\
\hline Subtotal $(I-$ squared $=17.2 \%, p=0.299)$ & $\ell$ & $1.65(1.55,1.76)$ & 100.00 \\
\hline \multicolumn{4}{|l|}{. } \\
\hline \multicolumn{4}{|l|}{ OR } \\
\hline Burg, 2007 & $\rightarrow$ & $2.30(1.40,3.90)$ & 2.36 \\
\hline Rodriguez, 2008 & $\rightarrow$ & $1.89(1.13,3.15)$ & 3.62 \\
\hline Jo, 2015 & $\rightarrow$ & $1.03(0.31,3.48)$ & 1.47 \\
\hline Mikkelsen, 2017 & $\leftarrow$ & $1.45(1.23,1.73)$ & 58.33 \\
\hline Rodriguez, 2010 & $\rightarrow$ & $2.10(1.20,4.80)$ & 1.14 \\
\hline Burg, 2007 & $\rightarrow$ & $1.00(0.60,1.60)$ & 14.72 \\
\hline Buss, 2012 & $\longrightarrow$ & $3.35(1.12,9.98)$ & 0.19 \\
\hline Li, 2016 & $\rightarrow$ & $1.43(1.05,1.95)$ & 18.17 \\
\hline Subtotal $(I$-squared $=0.2 \%, p=0.427)$ & 8 & $1.42(1.23,1.61)$ & 100.00 \\
\hline NOTE: Weights are from random effects a & & & \\
\hline
\end{tabular}

Fig. 3. Association between maternal prepregnancy obesity and the risk of attention deficit disorder with hyperactivity among children. $\mathrm{OR}$, odds ratio; $\mathrm{HR}$, hazard ratio; $\mathrm{Cl}$, confidence interval.

\section{Discussion}

This meta-analysis evaluated the association between maternal prepregnancy BMI and the risk of offspring ADHD in 8 individual studies. We found a statistically significant association between prepregnancy overweight and obesity and an increased risk of ADHD among children based on the pooled estimates of both HR and OR. This study showed that the risk of offspring ADHD increased by about 30\% in women with prepregnancy overweight status $42 \%$ and 65\% in women with prepregnancy obesity according to OR and $\mathrm{HR}$, respectively. In the subgroup analysis, there was no significant association in teacher-rated ADHD symptoms in the offsprings of 
Table 2. Results of the subgroup analysis of the maternal prepregnancy BMI and ADHD based on teacher/parent-identified ADHD symptoms in the USA and European countries (studies based on $\mathrm{OR}$ )

\begin{tabular}{|c|c|c|c|c|}
\hline \multirow{2}{*}{ Subgroups } & \multicolumn{4}{|c|}{ Studies } \\
\hline & No. of studies & BMl category & OR $(95 \% \mathrm{Cl})$ & $P^{2}$ \\
\hline \multicolumn{5}{|c|}{ By teacher/parents rated ADHD symptoms } \\
\hline \multirow[t]{2}{*}{ Parents } & 5 & Overweight & $1.26(1.12-1.41)$ & $0.0 \%$ \\
\hline & & Obese & $1.47(1.25-1.68)$ & $0.0 \%$ \\
\hline \multirow[t]{2}{*}{ Teacher } & 3 & Overweight & $1.33(0.95-1.70)$ & $24.3 \%$ \\
\hline & & Obese & $1.42(0.70-2.13)$ & $40.3 \%$ \\
\hline \multicolumn{5}{|c|}{ By European/USA countries } \\
\hline \multirow[t]{2}{*}{ European countries } & 5 & Overweight & $1.38(1.04-1.72)$ & $16.9 \%$ \\
\hline & & Obese & $1.25(1.11-1.40)$ & $0.0 \%$ \\
\hline \multirow[t]{2}{*}{ USA } & 3 & Overweight & $1.62(0.91-2.34)$ & $48.9 \%$ \\
\hline & & Obese & $1.44(1.23-1.66)$ & $0.0 \%$ \\
\hline
\end{tabular}

BMI, body mass index; $\mathrm{ADHD}$, attention deficit hyperactivity disorder; OR, odds ratio; $\mathrm{Cl}$, confidence interval.

overweight and obese women. This finding is important in terms of public health applications because it provides a new approach to preventing ADHD by controlling overweight and obesity in the prenatal period.

Some studies reported that maternal prepregnancy BMI is related to child ADHD and that it is not solely an artifact of effects that likely co-occur with maternal obesity. ${ }^{9,10)}$ Other studies claim that the contribution of maternal overweight/obesity to adverse brain development is affected in part by inflammatory phenomena. Therefore, inflammation may play a role in the association between maternal overweight/obesity and ADHD in children and adolescents. Leptin, which is released in accordance with the amount of adipose tissue, has an inflammatory effect. ${ }^{24)}$ Obese pregnant women have higher levels of pro-inflammatory cytokines in the circulation than their normal-weight counterparts. Also, placental and intrauterine inflammation is related to an altered fetal cytokine situation, fetal neuronal damage, and changes in the neonatal brain gene statement. Furthermore, the normal developmental trajectory of the fetal brain can be disrupted by exposure to infection and high levels of proinflammatory cytokines, producing long-term or constant outcomes for gray matter volume and white matter integrity. ${ }^{25,26)}$ This makes the fetus susceptible to psychiatric complications; therefore, $\mathrm{ADHD}$ is related to increased levels of inflammatory cytokines. ${ }^{27,28)}$

A meta-analysis conducted by Sanchez et al. ${ }^{29)}$ detailed the association of maternal obesity and diabetes with autism and other developmental disabilities. They reported that maternal overweight and obesity in prepregnancy were associated with ADHD in the offspring. However, they searched the PubMed and PsycINFO databases and found only 6 studies.

The present analysis revealed no significant association between teacher-identified ADHD symptoms among children and adolescents and prepregnancy overweight and obese status in women. The probable cause for this discrepancy between parent and teacher outcomes was differences in the settings for observing children between them. The child is seen by teacher in the structured environment of the classroom while medicated, whereas the parent has seen the child in the unstructured home setting while not medicated.

In this study, to understand the role of ethnicity on findings, we divided the enrolled studies into 2 categories (conducted in the USA vs. European countries). The results showed consistent association in the 2 subgroups. Therefore, this hypothesis is strengthened that ethnic differences may not play a role in this association.

Regarding clinical implications, we know that meta-analysis studies provide a precise and less biased estimate of the effect size with increased statistical power on a specific topic, which is important when the power of the primary study is limited because of a small sample size. Understanding how to conduct meta-analysis aids clinicians in the process of making clinical decisions. The results of our meta-analysis should be interpreted with clear understanding of their strengths and limitations. Regarding strengths, we first performed a systematic search of the major international databases, placing no restrictions on language, publication date, and document type. Second, according to the Newcastle-Ottawa Scale, all of the included studies were of high quality. Finally, the included studies typically were longitudinal cohorts with large sample sizes and adequate statistical power. There are also a number of limitations that should be considered. First, this meta-analysis was based on observational studies, the design of which is associated with inherent biases. Second, BMI measured in 4 studies was based on self-reports; thus, their validity is questionable. Third, the studies included in this meta-analysis were conducted in the USA and European countries, which might introduce data bias to this meta-analysis assessing the relationship between ADHD and prepregnancy BMI. This knowledge about the association between maternal overweight/ obesity and ADHD among children and adolescents can lead to an early assessment of children at risk and improve the methods of early diagnosis and intervention.

Epidemiological studies published to date provide sufficient 
evidence that prepregnancy overweight and obesity are significantly associated with an increased risk of ADHD among children and adolescents. These findings provide a new approach to preventing ADHD by controlling overweight and obesity in the prenatal period, which should be considered by policymakers.

\section{Conflicts of interest}

No potential conflict of interest relevant to this article was reported.

\section{Acknowledgments}

This research was supported by Hamadan University of Medical Sciences.

\section{References}

1. Adesman AR. The diagnosis and management of attention-deficit/ hyperactivity disorder in pediatric patients. Prim Care Companion J Clin Psychiatry 2001;3:66-77.

2. Polanczyk G, de Lima MS, Horta BL, Biederman J, Rohde LA. The worldwide prevalence of ADHD: a systematic review and metaregression analysis. Am J Psychiatry 2007;164:942-8.

3. Sciberras E, Mulraney M, Silva D, Coghill D. Prenatal risk factors and the etiology of ADHD-review of existing evidence. Curr Psychiatry Rep 2017;19:1.

4. Plomp E, Van Engeland H, Durston S. Understanding genes, environment and their interaction in attention-deficit hyperactivity disorder: is there a role for neuroimaging? Neuroscience 2009;164:230-40.

5. Nigg J, Nikolas M, Burt SA. Measured gene-by-environment interaction in relation to attention-deficit/hyperactivity disorder. J Am Acad Child Adolesc Psychiatry 2010;49:863-73.

6. Thapar A, Cooper M, Eyre 0, Langley K. What have we learnt about the causes of ADHD? J Child Psychol Psychiatry 2013;54:3-16.

7. Linnet KM, Dalsgaard S, Obel C, Wisborg K, Henriksen TB, Rodriguez A, et al. Maternal lifestyle factors in pregnancy risk of attention deficit hyperactivity disorder and associated behaviors: review of the current evidence. Am J Psychiatry 2003;160:1028-40.

8. Van Lieshout RJ, Taylor VH, Boyle MH. Pre-pregnancy and pregnancy obesity and neurodevelopmental outcomes in offspring: a systematic review. Obes Rev 2011;12:e548-59.

9. Rodriguez A, Miettunen J, Henriksen TB, Olsen J, Obel C, Taanila A, et al. Maternal adiposity prior to pregnancy is associated with ADHD symptoms in offspring: evidence from three prospective pregnancy cohorts. Int J Obes (Lond) 2008;32:550-7.

10. Rodriguez A. Maternal pre-pregnancy obesity and risk for inattention and negative emotionality in children. J Child Psychol Psychiatry 2010;51:134-43.

11. Rosenberg TJ, Garbers S, Lipkind H, Chiasson MA. Maternal obesity and diabetes as risk factors for adverse pregnancy outcomes: differences among 4 racial/ethnic groups. Am J Public Health 2005;95: 1545-51.
12. Peters JP, Hooft L, Grolman W, Stegeman I. Reporting quality of systematic reviews and meta-analyses of otorhinolaryngologic articles based on the PRISMA statement. PLoS One. 2015;10:e0136540.

13. World Health Organization. WHO global database on body mass index. Geneva (Switzerland): World Health Organization; 2014.

14. Wells GA, Shea B, O'Connell D, Peterson J, Welch V, Losos M, et al. The Newcastle-Ottawa Scale (NOS) for assessing the quality of nonrandomised studies in meta-analyses [Internet]. Ottawa (ON): Ottawa Hospital Research Institute; 2009 [cited 2017 Sep 15]. Available from: http://www.ohri.ca/programs/clinical_epidemiology/oxford.asp.

15. Egger M, Davey Smith G, Schneider M, Minder C. Bias in metaanalysis detected by a simple, graphical test. BMJ 1997;315:629-34.

16. Chen Q, Sjölander A, Långström N, Rodriguez A, Serlachius E, D'Onofrio BM, et al. Maternal pre-pregnancy body mass index and offspring attention deficit hyperactivity disorder: a population-based cohort study using a sibling-comparison design. Int J Epidemiol 2014;43:83-90.

17. Kong L, Norstedt G, Schalling M, Gissler M, Lavebratt C. The risk of offspring psychiatric disorders in the setting of maternal obesity and diabetes. Pediatrics 2018;142(3) [Epub]. pii: e20180776. https://doi. org/10.1542/peds.2018-0776.

18. Mikkelsen SH, Hohwü L, Olsen J, Bech BH, Liew Z, Obel C. Parental body mass index and behavioral problems in their offspring: a Danish National Birth Cohort Study. Am J Epidemiol 2017;186:593-602.

19. van der Burg JW, Jensen ET, van de Bor M, Joseph RM, O'Shea TM, Kuban K, et al. Maternal obesity and attention-related symptoms in the preterm offspring. Early Hum Dev 2017;115:9-15.

20. Andersen $\mathrm{CH}$, Thomsen PH, Nohr EA, Lemcke S. Maternal body mass index before pregnancy as a risk factor for ADHD and autism in children. Eur Child Adolesc Psychiatry 2018;27:139-48.

21. Jo H, Schieve LA, Sharma AJ, Hinkle SN, Li R, Lind JN. Maternal prepregnancy body mass index and child psychosocial development at 6 years of age. Pediatrics 2015;135:e1198-209.

22. Buss C, Entringer S, Davis EP, Hobel CJ, Swanson JM, Wadhwa PD, et al. Impaired executive function mediates the association between maternal pre-pregnancy body mass index and child ADHD symptoms. PLoS One 2012;7:e37758.

23. Li M, Fallin MD, Riley A, Landa R, Walker SO, Silverstein M, et al. The association of maternal obesity and diabetes with autism and other developmental disabilities. Pediatrics 2016;137:e20152206.

24. Valleau JC, Sullivan EL. The impact of leptin on perinatal development and psychopathology. J Chem Neuroanat 2014;61-62:221-32.

25. Short SJ, Lubach GR, Karasin AI, Olsen CW, Styner M, Knickmeyer $\mathrm{RC}$, et al. Maternal influenza infection during pregnancy impacts postnatal brain development in the rhesus monkey. Biol Psychiatry 2010;67:965-73.

26. Willette AA, Lubach GR, Knickmeyer RC, Short SJ, Styner M, Gilmore $\mathrm{JH}$, et al. Brain enlargement and increased behavioral and cytokine reactivity in infant monkeys following acute prenatal endotoxemia. Behav Brain Res 2011;219:108-15.

27. Sullivan EL, Nousen EK, Chamlou KA. Maternal high fat diet consumption during the perinatal period programs offspring behavior. Physiol Behav 2014;123:236-42.

28. Kang SS, Kurti A, Fair DA, Fryer JD. Dietary intervention rescues maternal obesity induced behavior deficits and neuroinflammation in offspring. J Neuroinflammation 2014;11:156.

29. Sanchez CE, Barry C, Sabhlok A, Russell K, Majors A, Kollins SH, et al. Maternal pre-pregnancy obesity and child neurodevelopmental outcomes: a meta-analysis. Obes Rev 2018;19:464-84. 